\title{
Are income poverty and perceptions of financial difficulties dynamically interrelated? *
}

\author{
SARA AYLLÓN \\ Department of Economics \\ Universitat de Girona and EQUALITAS, Spain \\ Alessio Fusco \\ CEPS/INSTEAD, Luxembourg
}

October 31, 2013

\begin{abstract}
The economic well-being of an individual can be measured in several ways. The standard income poverty approach aims at determining objectively whether individuals' income fall short from a pre-defined income poverty line. Alternatively, one may rely on subjective information about perceived financial difficulties to assess individuals' welfare. Income poverty and perceived financial difficulties are therefore complementary concepts based on different types of information. Knowledge about how these two concepts are dynamically interrelated is however limited. By estimating dynamic bivariate models controlling for state dependence, unobserved heterogeneity and initial conditions, we precisely aim at determining whether there are dynamic cross-effects between both concepts implying for example that past income poverty influence current perception of financial difficulties. The data used for our empirical application are those from the Luxembourg Socio-economic panel "Liewen zu Lëtzebuerg" (PSELL3) for the years 2003 to 2011.
\end{abstract}

\section{Keywords:}

JEL classification: D31, D60, I32

\footnotetext{
*Ayllón gratefully acknowledges financial support from the Spanish project SEJXXX and XREPP (Direcció General de Recerca). Fusco gratefully acknowledges financial support by the Luxembourg Fonds National de la Recherche through the funding of the PersiPov project (contract C10/LM/783502) and by core funding for CEPS/INSTEAD from the Ministry of Higher Education and Research of Luxembourg. This is a preliminary and incomplete draft. Please do not quote!
} 


\section{Introduction}

The economic well-being (or financial adequacy) of an individual can be measured in several ways. The conventional income poverty approach aims at determining objectively whether individuals' income fall short from a pre-defined income poverty line. Concern about this approach is sometimes expressed for practical reasons, such as measurement error (e.g. Nicoletti, Peracchi, and Foliano, 2011) or difficulties in identifying relevant poverty lines or equivalence scales (e.g. Ravallion, 1996). On more substantive ground, objective approaches may miss part of the problem. For example, Bourguignon (2006) highlights the following paradox in developed countries: while the presence of an efficient redistribution system was successful in reducing the level of poverty, a 'feeling' of poverty is still often reported in some population subgroups such as beneficiaries of minimum income guarantee programs. ${ }^{1}$ Henceforth, the concept of poverty or welfare is certainly broader than that of low income only. This probably explains why one of the alternatives to the income poverty approach consists in relying on subjective information about perceived financial difficulties to assess individuals' welfare (Deaton, 2010, Kaya, 2013).

Therefore, income poverty and perceptions of financial difficulties are concepts aiming at measuring similar phenomenon on the basis of different types of information. However, in addition to highlighting different aspects of disadvantage, these two concepts are likely interrelated. The objective situation unveiled by the income poverty approach directly influences individuals' perception. Current perceptions can be influenced not only by current objective situation, but also by the objective situation in previous periods. Our empirical knowledge about the extent to which these two concepts are dynamically interrelated is however limited. One of the aim of the paper is precisely to analyse this question.

When analysing the determinants of individual welfare, a key element is to take into account longitudinal aspects. In particular, an element that received considerable attention in the literature is the issue of state dependence, that is the extent to which being poor in a given moment increases by itself the probability of being poor in the future (Heckman, 2001, Skrondal and Rabe-Hesketh, 2013). As well established in the literature, both income poverty (see among others Cappellari and Jenkins, 2004, Biewen, 2009, Fusco and Islam, 2012, Ayllón, 2013b) and perceived financial difficulties (e.g. Pudney, 2008, Newman, Delaney, and Nolan, 2008, Kaya, 2013) are affected by a considerable degree of state dependence. Regarding income poverty, this empirical regularity can be explained by a behavioral effect of past poverty on current poverty. Biewen (2009) proposes several mechanisms to explain such a genuine effect: i) adverse incentives in countries with a minimum-income guarantee, ii) demoralization or depreciation of human capital, (iii) potential health,

\footnotetext{
${ }^{1}$ Moreover, as emphasized by Bourguignon $(2006,77)$ to some extent, "income transfers may even worsen the situation as they may stigmatize their beneficiaries. [..] Reducing poverty is certainly desirable but it may fail to eliminate a feeling of social deprivation that may be rooted in deeper causes".
} 
drug or alcohol problems, (iv) bad networking or (v) household split. In the case of subjective variables, such as perceived financial difficulties, Pudney (2008) relates the issue of state dependence to the question of inertia of perceptions, that is the time necessary for perceptions to adjust to change in circumstances (see also Bottan and Perez Truglia, 2011, Wunder, 2012). Full inertia occurs if today's perception is completely determined by yesterday's perception and not by change in circumstances. If this is the case, perceptions might not be good indicators of current well-being. By contrast, full adjustment means that current perceptions are not affected by previous perceptions and changes in perceptions can be fully ascribed to changes in circumstances rather than to long term circumstances; perceptions can then be considered a good indicator of current well-being. The true situation usually lies in between these two extreme cases which highlights that in the case of perceptions, as in the case of income poverty, modelling state dependence is crucial to avoid the potential bias that estimating static models would yield.

State dependence refers to the question as to whether a concept is autoregressive. Another way through which the past can affect the present is through feedback effects of some covariates (Biewen, 2009). For example, past income poverty may affect current perceptions of financial difficulties, especially in the case where perceived financial difficulties display some inertia. ${ }^{2}$ Similarly, past perceived financial difficulties may affect current income poverty through discouragement effects. The extent to which this is the case is ultimately an empirical question. While the literature regarding the analysis of the dynamics of income poverty is large (e.g. Jenkins, 2011), more scarce but still existing regarding the dynamics of perceived financial difficulties (Pudney, 2008, Newman, Delaney, and Nolan, 2008, Kaya, 2013, Fusco, 2013), to our knowledge there are no econometric attempts to characterize the joint dynamics of objective and subjective financial difficulties.

While analysing the interrelationship of both concepts is interesting per se, it also allows us to analyse the effect of some covariates on both concepts simultaneously. For example, on the basis of separated models applied to the same Luxembourgish sample, Fusco and Islam (2012) find that an additional child aged between 12 and 17 years old increase the probability of entering income poverty while Fusco (2013) finds that it has no effect on the probability of entering perceived financial difficulties. Analysing the impact of the presence of older children on both concepts simultaneoulsy may shed a different light on this result.

Subjective variables are typically ordinal variables. An additional contribution of the paper is that we consider different modelling assumptions of the subjective variable to assess the robustness of the results. In particular, we compare the results obtained when dichotomozing the subjective variable with those obtained when

\footnotetext{
${ }^{2}$ In the case of happiness, Bottan and Perez Truglia (2011) make the distinction between two channels of habituation: general habituation (or satisfaction treadmill) refers to genuine state dependence while specific habituation (or hedonic treadmill) refers to habituation to specific lagged effects of life events. For an analysis of the adaptation of happiness to poverty see Clark, D'Ambrosio, and Ghislandi (2013).
} 
making full use of the available information and using the ordinal variable. While Newman, Delaney, and Nolan (2008) apply this strategy to analyse the question of state dependence in financial well being, to our knowledge our paper is the first one doing so in the context of a dynamic bivariate model. ${ }^{3}$

Our empirical illustration is based on Luxemburg data. Following the development of the financial sector since the middle of the 1980s, Luxembourg became one of the richest countries in terms of GDP per capita (see e.g. Fusco, Van Kerm, Alieva, Bellani, Etienne-Robert, Guio, Kyzyma, Leduc, Ligeois, Pi Alperin, Reinstadler, Sierminska, Sologon, Thill, Valentova, and Voicu, 2013). It may then appear surprising to devote efforts in studying financial difficulties in this country. However, it can also be argued that subjective approaches bring valuable information that can be relevant precisely in a rich country as Luxembourg, given that they are likely to capture the feeling of social exclusion referred to by Bourguignon (2006).

By estimating dynamic bivariate models controlling for unobserved heterogeneity and initial conditions (e.g. Devicienti and Poggi, 2011), we aim at determining whether both concepts are characterized by state dependence and whether there are dynamic cross-effects implying for example that past income poverty influence current perception of financial difficulties. The results of our empirical illustration indicate that this is the case but vary according to some specifications. When focus on binary status variables, no evidence of feedback effect from past income poverty (perceived financial difficulties) on current perceived financial difficulties (income poverty) was found. However, such cross-effects appeared when modelling perceived financial difficulties as an ordinal variable.

The paper is organized as follows. Section 2 presents the data used extracted from the Luxembourg Socio-economic panel "Liewen zu Lëtzebuerg" (PSELL3) for the years 2003 to 2011 as well as some descriptive statistics. The methodology applied is presented in Section 3 while section 4 contains the results. Finally, Section 5 concludes.

\section{Data and descriptives}

Our empirical application is based on the Luxemburg Socio-Economic Panel "Liewen zu Lëtzebuerg" (PSELL3) which is the Luxemburgish component of the European Union-Statistics on Income and Living Conditions (EU-SILC). PSELL3 is running since 2003 when it was launched, with an initial sample of around 3500 households and 10000 individuals and contains information about residents' incomes, living conditions and other personal and household characteristics. PSELL3 provides repeated annual observations since 2003 on the same individuals which makes it possible to link changes in poverty status with changes in household circumstances such as family arrangements or labour market situations. In this paper, we use the nine waves

\footnotetext{
${ }^{3}$ Amuedo-Dorantes and Serrano-Padial (2010) use a multinomial regression to model labour flexibility.
} 
of the PSELL3 data covering the years 2003 to 2011.

The ordinal variable we focus on in this paper is the following: "A household may have different sources of income and more than one household member may contribute to it. Thinking of your household's total income, is your household able to make ends meet, namely, to pay for its usual necessary expenses". We have recoded the variable that takes the values 0 .Very easily; 1 .Easily; 2 .Fairly easily; 3 .With some difficulty; 4.With difficulty; 5.With great difficulty. We assume that each household has the same interpretation of each modality. We attributed this household level question to each of the household member as is typically done in the income poverty literature and also by other authors (e.g. Taylor, 2011). Regarding poverty, an individual is considered poor if he belongs to a household whose equivalent income is lower than $60 \%$ of the median equivalised income.

Our focus is on the adult population aged between 20 and 59. Students, military and pensioners are excluded from the analysis because these population subgroups are very specific and concern about the reliability of their answers regarding their perceived financial difficulties is sometimes expressed. For example, elderly people are usually found to underestimate the financial difficulties they are confronted too. Indeed, a result often highlighted in the literature is that elderly people often consider their income as adequate, even when this income is in fact very low (e.g. Stoller and Stoller, 2003, Litwin and Sapir, 2009).

Table 1 shows the distribution of perceived financial inadequacy and the poverty rate for the studied sample and across the analysed period. In Luxembourg, the great majority of individuals finds it 'easy' to make ends meet (on average 36\%) or 'fairly easy' (31\%). ${ }^{4}$ Only about $10 \%$ of the studied sample answers that they can make ends meet 'very easily'. Moreover, note that a sizeable group of nearly $8 \%$ of the individuals declares that to make ends meet is 'difficult' or 'very difficult' and about $15 \%$ say that it is 'quite difficult'. From this point, we will consider that individuals are in financial difficulties if they answer 'difficult' or 'very difficult' to the aforementioned question. On average, $7.6 \%$ of the sample is found to be in financial difficulties, a percentage that evolves between $6 \%$ and $9 \%$ across the period. Last column shows the income poverty rate which was of $10.6 \%$ in 2003 and then evolved between $12 \%$ and $14 \%$ in the period 2004 to 2011.

Table 2 analyses the joint distribution of both concepts across time. As shown, between $3 \%$ and $5 \%$ of the individuals in the sample are both income poor and in perceived financial difficulties. The percentage is very similar for those individuals that declare to be in financial difficulties but are not income poor (on average $3.8 \%$ ). Instead, $9.5 \%$ of individuals do not state to be in financial difficulties but are considered income poor. In total, an average of $17.1 \%$ of the sample is affected by either one or both phenomena. Moreover, Table 3 indicates that $28.4 \%$ of the income poor perceive themselves in financial difficulties, while only $4.4 \%$ of the non income poor are in such a situation. ${ }^{5}$ These pooled results indicate that the overlap

\footnotetext{
${ }^{4}$ Figures on the overall population are similar and can be found in STATEC (2013).

${ }^{5}$ Conversely, close to $50 \%$ of the individuals in perceived financial difficulties are income poor,
} 
Table 1: Distribution of perceived financial difficulties and poverty rate, per year

\begin{tabular}{cccccccc}
\hline \multirow{2}{*}{ Wave } & \multicolumn{6}{c}{ Perceived financial difficulties } & Poor \\
\cline { 2 - 6 } & $\begin{array}{c}\text { very } \\
\text { easily }\end{array}$ & easily & $\begin{array}{c}\text { fairly } \\
\text { easily }\end{array}$ & $\begin{array}{c}\text { quite } \\
\text { difficult }\end{array}$ & difficult & $\begin{array}{c}\text { very } \\
\text { difficult }\end{array}$ & \\
\hline 1 & 11.2 & 37.2 & 30.5 & 13.9 & 5,3 & 1.9 & 10.6 \\
2 & 13.9 & 36.0 & 29.4 & 14,1 & 4.8 & 1.9 & 13.0 \\
3 & 12.3 & 38.6 & 28.6 & 14,1 & 4.6 & 1.7 & 12.7 \\
4 & 10.7 & 37.5 & 32.3 & 13,8 & 4.3 & 1.5 & 13.1 \\
5 & 9.8 & 38.7 & 30.5 & 14,2 & 5.0 & 1.9 & 12.9 \\
6 & 9.1 & 37.7 & 30.1 & 15,5 & 5.7 & 2.0 & 13.4 \\
7 & 8.8 & 33.7 & 31.9 & 17,6 & 5.9 & 2.1 & 14.4 \\
8 & 7.9 & 34.7 & 32.7 & 15,8 & 6.6 & 2.3 & 14.5 \\
9 & 9.2 & 32.0 & 32.3 & 17,1 & 6.6 & 2.8 & 13.3 \\
\hline Total & $\mathbf{1 0 . 1}$ & $\mathbf{3 5 . 9}$ & $\mathbf{3 1 . 1}$ & $\mathbf{1 5 . 3}$ & $\mathbf{5 . 5}$ & $\mathbf{2 . 1}$ & $\mathbf{1 3 . 2}$ \\
\hline
\end{tabular}

Source: PSELL3/EU-SILC, 2003-2011, authors computation. Weighted results.

between the two measures is not perfect which suggests that the two definitions of financial difficulties, subjective or objective, are complementary. Sample size is also shown in the last column.

Table 2: Joint distribution of financial difficulties and income poverty

\begin{tabular}{cccccc}
\hline Wave & $\begin{array}{c}\text { Not poor, } \\
\text { nor in FD }\end{array}$ & $\begin{array}{c}\text { Income } \\
\text { poor only }\end{array}$ & $\begin{array}{c}\text { In FD } \\
\text { only }\end{array}$ & Both & N \\
\hline 1 & 85.3 & 7.5 & 4.0 & 3.1 & 4951 \\
2 & 83.6 & 9.7 & 3.4 & 3.3 & 5055 \\
3 & 83.6 & 10.1 & 3.8 & 2.6 & 5089 \\
4 & 84.1 & 10.2 & 2.7 & 3.0 & 5455 \\
5 & 84.3 & 8.9 & 2.8 & 4.1 & 5582 \\
6 & 82.9 & 9.4 & 3.7 & 3.9 & 5412 \\
7 & 81.6 & 10.4 & 4.0 & 4.0 & 5891 \\
8 & 81.4 & 9.7 & 4.1 & 4.8 & 6684 \\
9 & 81.4 & 9.2 & 5.3 & 4.2 & 7522 \\
\hline Total & $\mathbf{8 3 . 0}$ & $\mathbf{9 . 5}$ & $\mathbf{3 . 8}$ & $\mathbf{3 . 8}$ & $\mathbf{5 1 6 4 1}$ \\
\hline
\end{tabular}

Source: PSELL3/EU-SILC, 2003-2011, authors computation. Weighted results.

Previous results were based on cross-sectional data. We now turn to the longitudinal dimension.

while only $10 \%$ of individuals having difficulties to make ends meet are found in poverty (not shown for brevity). 
Table 3: Probablility of being in financial difficulties given poverty status at the same year

\begin{tabular}{lrrrr}
\hline & \multicolumn{3}{c}{ Perceived financial difficulties at $t$} \\
\cline { 3 - 5 } & & Not in FD & In FD & Total \\
\hline \multirow{2}{*}{ Poverty at $t$} & Not poor & 95.6 & 4.4 & 100.0 \\
& Poor & 71.6 & 28.4 & 100.0 \\
\cline { 2 - 5 } & Total & $\mathbf{9 2 . 4}$ & $\mathbf{7 . 6}$ & $\mathbf{1 0 0 . 0}$ \\
\hline
\end{tabular}

Source: PSELL3/EU-SILC, 2003-2011, authors computation. Weighted results. Pooled observations across the period.

In terms of transitions, first panel of Table 4 shows the probability of being in financial difficulties given the status in the same problem the previous year. Note that $45.9 \%$ of the individuals initially in perceived financial difficulties remain in the same situation, compared to $4.3 \%$ of the initially non in perceived financial difficulty. The same percentages in the case of income poverty are $68.4 \%$ and $4.5 \%$, respectively, as shown in the second panel of the same table. This suggests a sizeable scarring effect (state dependence) for both concepts, especially strong in the case of income poverty.

Table 4: Probablility of being in financial difficulties at $t$ given status at $t-1$ and probability of being poor at $t$ given status at $t-1$

\begin{tabular}{crrrr}
\hline & & \multicolumn{3}{c}{ Perceived FD at $t$} \\
\cline { 3 - 5 } Perceived FD at $t-1$ & Not in FD & In FD & Total \\
& Not in FD & 95.8 & 4.3 & 100.0 \\
& In FD & 54.1 & 45.9 & 100.0 \\
\cline { 3 - 5 } & Total & $\mathbf{9 2 . 8}$ & $\mathbf{7 . 2}$ & $\mathbf{1 0 0 . 0}$ \\
\hline & & \multicolumn{3}{c}{ Poverty at $t$} \\
\cline { 3 - 5 } Poverty at $t-1$ & Not poor & Not poor & Poor & Total \\
\hline \multirow{2}{*}{ Noryyy} & Poor & 31.6 & 68.5 & 100.0 \\
\cline { 2 - 5 } & Total & $\mathbf{8 7 . 2}$ & $\mathbf{1 2 . 8}$ & $\mathbf{1 0 0 . 0}$ \\
\hline
\end{tabular}

Source: PSELL3/EU-SILC, 2003-2011, authors computation. Weighted results. Pooled observations across the period.

Looking at the relation between the two concepts in consecutive years, in Table 5 , we can see that lagged income poverty and current perceived financial difficulties are linked: the conditional probability of being currently in perceived financial difficulty is $26.2 \%$ for the initially poor, while it is only $4.4 \%$ for the initially non poor. The relative risk is of 5.96. The relative risk of being income poor depending on the 
previous perceived financial difficulties status is of 5.4 (the probability of being currently income poor for the initially in perceived financial difficulty is $52.5 \%$; for the initially non poor it is of $9.7 \%$ ).

Table 5: Probablility of being in financial difficulties at $t$ given poverty status at $t-1$ and probability of being poor given status in perceived financial difficulties at $t-1$

\begin{tabular}{crrrr}
\hline & & \multicolumn{3}{c}{ Perceived FD at $t$} \\
\cline { 3 - 5 } Poverty at $t-1$ & Not in FD & In FD & Total \\
\hline \multirow{2}{*}{ Not poor } & 95.6 & 4.4 & 100.0 \\
& Poor & 73.8 & 26.2 & 100.0 \\
\cline { 3 - 5 } & Total & $\mathbf{9 2 . 8}$ & $\mathbf{7 . 2}$ & $\mathbf{1 0 0 . 0}$ \\
\hline \multirow{2}{*}{ Perceived FD at $t-1$} & & \multicolumn{3}{c}{ Poverty at $t$} \\
\cline { 3 - 5 } & Not in FD & Not poor & Poor & Total \\
\cline { 3 - 5 } & In FD & 90.3 & 9.7 & 100.0 \\
& Total & $\mathbf{8 7 . 2}$ & $\mathbf{1 2 . 8}$ & $\mathbf{1 0 0 . 0}$ \\
\hline
\end{tabular}

Source: PSELL3/EU-SILC, 2003-2011, authors computation. Weighted results. Pooled observations across the period.

These descriptive statistics suggest that both concepts display state dependence and are related dynamically. Whether these descriptives are the results of individual heterogeneity or of causal mechanisms is an empirical question we try to disentangle in the next section.

\section{Methodology}

We propose two econometric strategies for the study of the interrelationship between poverty and perceived financial difficulties. In the first place, we estimate jointly a dynamic random effects probit for the subjective assessment of own financial situation $\left(S_{i t}\right)$ and a dynamic random-effects probit for income poverty $\left(P_{i t}\right)$. The second strategy, instead of using a dichotomised dependent variable, we make use of all the information available in the data set and we estimate $S_{i t}$ by means of a dynamic random-effects ordered probit.

Formally, both equations can be written as follows:

$$
\begin{gathered}
S_{i t}^{*}=\alpha S_{i t-1}+\beta P_{i t-1}+\gamma^{\prime} X_{i t}+u_{i}+\epsilon_{i t} \\
P_{i t}^{*}=\chi P_{i t-1}+\delta S_{i t-1}+\eta^{\prime} Z_{i t}+v_{i}+\mu_{i t}
\end{gathered}
$$

where $i=1,2, \ldots, N$ are individuals and $t=2, \ldots, T$ are the number of periods under study. 
We assume that in period $t$, individuals can be characterised by a latent propensity for perceived financial difficulties, $S_{i t}^{*}$, that takes the form:

$$
S_{i t}=I\left(S_{i t}^{*}>0\right)
$$

where $I\left(S_{i t}^{*}>0\right)$ is a binary indicator function that equals one if the latent propensity is positive and equals zero otherwise.

In the case of the ordered variable, the latent outcome $S_{i t}^{*}$ is not observed but we do have an indicator of the category in which the latent category falls, $S_{i t}$. Thus,

$$
S_{i t}=j \quad \text { if } \quad \mu_{j-1}<S_{i t}^{*} \leq \mu_{j-1}, \quad j=1, \ldots, m
$$

where $\mu_{0}=-\infty, \mu_{j} \leq \mu_{j+1}, \mu_{m}=\infty$. As explained above, perceived financial difficulties is a variable with six categories $(j)$.

The same assumptions are done in the case of poverty with

$$
P_{i t}=I\left(P_{i t}^{*}>0\right)
$$

and $I\left(P_{i t}^{*}>0\right)$ being a binary indicator function that equals one if the latent propensity is positive and equals zero otherwise.

As well established in the literature, both poverty and perceived financial difficulties are affected by a considerable degree of state dependence. That is, being poor in a given moment increases by itself the probability of being poor in the future (see among others Cappellari and Jenkins, 2004, Biewen, 2009, Fusco and Islam, 2012, Ayllón, 2013b). Similarly, Pudney (2008), Newman, Delaney, and Nolan (2008), Kaya (2013) find that history matters also regarding the subjective perceptions of own financial situation which suggests that the adjustment of indviduals' perceptions of financial difficulties is not immediate. Thus, the one year lag of each variable assures the control over state dependence and we expect $\alpha$ and $\chi$ to be positive and statistically significant.

In order to take into account the possible interrelationship between poverty and perceived financial difficulties, we introduce a feedback effect in each equation that will asssess the degree of dependence between both phenomena. That is, $\beta$ will control for the influence of past poverty on current perceived financial difficulties. We expect $\beta$ to be positive and statistically significant showing that a year in poverty harms the current subjective perception of own financial situation. In a similar fashion, $\delta$ that captures the influence of past financial difficulties on current poverty status is likely to be positive and precisely estimated indicating that households that perceive that they have difficulties to make ends meet are more likely to be found in poverty today. ${ }^{6}$ Furthermore, we consider the possibility that current poverty status $P_{i t}$ enters as an explanatory variable in the perceived financial difficulties equation

\footnotetext{
${ }^{6}$ Buddelmeyer and Cai (2009) use a similar strategy to study the interrelationship between health and poverty. In their case, they introduce the lagged value of poverty in a health equation while current health (not lagged) in the poverty equation. Their argument is that the effect of health on income is immediate while the effect of income on health is slow. This is hardly plausible
} 
to assess the importance of the relationship between both phenomena at the current period. ${ }^{7}$ In that case, the equations (1) and (2) can be written in the following way:

$$
\begin{array}{r}
S_{i t}^{*}=\alpha S_{i t-1}+\theta P_{i t}+\beta P_{i t-1}+\gamma^{\prime} X_{i t}+u_{i}+\epsilon_{i t} \\
P_{i t}^{*}=\chi P_{i t-1}+\delta S_{i t-1}+\eta^{\prime} Z_{i t}+v_{i}+\mu_{i t}
\end{array}
$$

$X_{i t}$ and $Z_{i t}$ are the explanatory variables that are expected to affect both process. They reflect the demographic and working characteristics of the household and of the individual that live in and refer to the individual (age, age squared, gender, citizenship, employment status, health status, marital status, education) and the household (household composition, the attachment to the labour market, tenure status). In the case of perceived financial difficulties, we expect variables suggesting additional financial resources (e.g. an additional individual at work) to decrease the risk of being in perceived financial difficulties through a risk diversification effect, while variables reflecting additional expenditures (henceforth increasing the (perception of) resources needed), such as an additional child, are expected to increase the risk of being in perceived financial difficulties

In order to take into account unobserved heterogeneity, both equations follow Wooldridge (2005) in the treatment of initial conditions. The control over unobserved heterogeneity is important in the type of models as the one presented here because otherwise state dependence is overestimated (see, for example, Weber (2002)). Moreover, the inclusion of an individual specific effect results in an initial conditions problem: we cannot know whether the observed phenomena started even before each individual entered the survey. That is, we need to control that each initial condition is correlated with the individual specific effect $\left(u_{i}\right.$ and $v_{i}$, respectively). Ignoring the initial conditions problem would result in inconsistent estimates.

Wooldridge (2005) proposes to find the density of the dependent variables from $t=2, \ldots, T$ conditional of the initial conditions and the explanatory variables. That is, we specify the density of the unobserved specific effect conditional on the dependent variables at $t=1$. Formally, we can write the specification as follows,

$$
\begin{array}{r}
u_{i}=a_{0}+a_{1} P_{i 0}+a_{2} S_{i 0}+a_{4} \overline{X_{i}}+\kappa_{i} \\
v_{i}=b_{0}+b_{1} S_{i 0}+b_{2} P_{i 0}+b_{4} \overline{Z_{i}}+\nu_{i}
\end{array}
$$

in the case of our analysis. Other applications of this methodology can be found in Alessie, Hochguertel, and Van Soest (2004), Cai and Kalb (2006), Cai (2009), Haan and Myck (2009), Amuedo-Dorantes and Serrano-Padial (2010), Cai (2010), Devicienti, Groisman, and Poggi (2010), Rochut and Van Kerm (2010), Devicienti and Poggi (2011), Heiss (2011), Michaud and Tatsiramos (2011).

${ }^{7}$ Note we do not consider that perceived financial difficulties influence current poverty as we consider that the objective situation is prior to the subjective evaluation so that simultaneous effects are ruled out. In our dynamic framework, the objective situation can only be influenced by feedback effects from past perceptions and not by current effects. The effect of income poverty on perceived financial dificulties is immediate while the effect of perceived financial difficulties on income poverty is delayed. 
Following Stewart (2007), we add the means of the time-varying explanatory variables in order to allow a certain degree of correlation between the independent variables and the individual specific effect (see also Mundlak, 1978, Alessie, Hochguertel, and Van Soest, 2004). $\kappa$ and $\nu$ will be integrated out using GaussHermite quadrature with 12 points in order to get consistent estimates. Estimates of the model parameters are obtained by Conditional Maximum Likelihood (CML).

Finally, the error terms include each a white noise error that changes over time ( $\epsilon_{i t}$ and $\mu_{i t}$ respectively) assumed to follow a normal distribution with zero mean and unit variance, with a variance-covariance matrix named $\sum$ and correlation called $\rho$. Given that the error term comprises also an (additive) individual specific effect in each equation $u_{i}$ and $v_{i}$ assumed to be bivariate normal, we can define a variance-covariance matrix as follows,

$$
\left(\begin{array}{cc}
\sigma_{\kappa_{i}}^{2} & \\
\rho_{\kappa_{i}, \nu_{i}} & \sigma_{\nu_{i}}^{2}
\end{array}\right)
$$

If $\rho$ is positive, it means that unobservables that make individuals more likely to be poor also make them more likely to perceive that they have great financial difficulties to make ends meet. ${ }^{8}$

\section{Empirical results}

Table 6 reports the estimates of equations (1) and (2). The first two columns show the results of the bivariate random effects (RE) probit models with simple feedback effects for perceived financial difficulties and poverty. The third and fourth columns detail the results when 'perceived financial difficulties' is modelled by means of an ordered RE probit.

The positive and highly significant coefficients for $S_{i t-1}$ on $S_{i t}\left(0.45^{* * *}\right)$ and $P_{i t-1}$ on $P_{i t}\left(0.74^{* * *}\right)$ indicate that both phenomena are affected by a considerable degree of genuine state dependence as already found in the literature (see Section 3). That is, perceiving financial difficulties in the past increases by itself the probability of being in the same situation in the future. The results can be read similarly in the case of poverty. Average Partial Effects (APEs) show that, for example, being in poverty in a given year increases by XX percentage points the probability of experiencing poverty in the following period. The same percentage is of XX points in the case of perceived financial difficulties. Noticeably, the coefficient for the initial conditions in both equations is greater than the lagged which indicates a considerable correlation between the unobserved heterogeneity effect and the initial conditions. These results are confirmed by Model 2, that is when perceived financial difficulties are modelled using a ordered RE probit.

Turning to the feedback effects, results in the first columns would seem to indicate that past perceived financial difficulties have no influence on current poverty

\footnotetext{
${ }^{8}$ The model is estimated using the software aML (see e.g. Ayllón, 2013a).
} 
Table 6: Main results for the bivariate RE probits for $S_{t}$ and $P_{t}$ (Model 1) and the ordered RE probit model for $S_{t}$ and bivariate RE probit for $P_{t}$ (Model 2)

\begin{tabular}{lll|ll}
\hline \multicolumn{2}{c|}{ Model 1 } & \multicolumn{2}{c}{ Model 2} \\
\hline & $S_{t}$ & $P_{t}$ & $S_{t}$ & $P_{t}$ \\
\hline$S_{t-1}$ & $0,45^{* * *}$ & 0,078 & & \\
$S_{t-1}[1]$ & & & $0,47^{* * *}$ & $-0,19^{* * *}$ \\
$S_{t-1}[2]$ & & & $0,73^{* * *}$ & $-0,20^{* * *}$ \\
$S_{t-1}[3]$ & & & $1,10^{* * *}$ & $-0,11$ \\
$S_{t-1}[4]$ & & & $1,28^{* * *}$ & $-0,09$ \\
$S_{t-1}[5]$ & & & $1,34^{* * *}$ & $-0,07$ \\
$S_{0}$ & $0,77^{* * *}$ & $0,40^{* * *}$ & & \\
$S_{0}[1]$ & & & $0,67^{* * *}$ & $0,26^{* * *}$ \\
$S_{0}[2]$ & & & $1,27^{* * *}$ & $0,47^{* * *}$ \\
$S_{0}[3]$ & & & $1,81^{* * *}$ & $0,75^{* * *}$ \\
$S_{0}[4]$ & & & $1,99^{* * *}$ & $0,89^{* * *}$ \\
$S_{0}[5]$ & & & $2,33^{* * *}$ & $1,02^{* * *}$ \\
$P_{t-1}$ & 0,006 & $0,74^{* * *}$ & $0,07^{* * *}$ & $0,73^{* * *}$ \\
$P_{0}$ & $0,32^{* * *}$ & $0,93^{* * *}$ & $0,21^{* * *}$ & $0,85^{* * *}$ \\
\hline eps1 & \multicolumn{2}{c|}{$0,74^{* * *}$} & \multicolumn{2}{c}{$0,68^{* * *}$} \\
eps2 & $0,77^{* * *}$ & \multicolumn{2}{|c}{$0,78^{* * *}$} \\
\hline rho & \multicolumn{2}{|c|}{$0,47^{* * *}$} & \multicolumn{2}{c}{$03^{* * *}$} \\
\hline
\end{tabular}

Source: PSELL3/EU-SILC, 2003-2011, authors computation. 
and that past poverty has no effect on today's feeling of financial difficulties. As a matter of fact, both phenomena would seem to be only related through the initial conditions. However, results from the RE ordered probit that is, when we make use of all the information available in the data set, show the existence of a interrelationship between both phenomena. Past poverty increases the probability of current perceived financial difficulties $\left(0.07^{* * *}\right)$. And, at the same time, past perceived financial difficulties reduce the probability of feeling that it is 'easy' of 'fairly easy' to make ends meet. Note however that the results are only precisely estimated for the groups perceiving no financial difficulties while no difference is found for the individuals finding it 'quite difficult', 'difficult' or 'very difficult'.

The standard deviations of the random effects are highly significant indicating the importance of controlling for unobserved heterogeneity in both cases. Finally, note that the correlation between unobservables related to perceived financial difficulties and those related to poverty are positively correlated. This indicates that unobservables that make a family more likely to perceive that they are in financial difficulties also make them more likely to be found below the poverty line.

Table 7 shows the results when current poverty status $\left(P_{t}\right)$ is included in the 'perceived financial difficulties' equation. The idea is that today's financial difficulties are very much likely to be affected not only by past poverty experiences but also by the current economic situation of the family.

The results on state dependence for both phenomena do not change and coefficients are very similar to those of Table 6 and they keep the same level of statistical significance. The coefficient for $P_{t}$ on $S_{t}$ is positive and precisely estimated which tells about the direct relationship between current poverty and perceived financial difficulties. This results is common to both model specifications.

Interestingly, note that the introduction of $P_{t}$ on $S_{t}$ has changed the significance of the feedback from $S_{t-1}$ on $P_{t}$ which is now positive and statistically significant at $99 \%$ in Model 3. If we turn our attention to Model 4, we can observe that it is the feedback from $P_{t-1}$ on $S_{t}$ that is positive and precisely estimated and instead the coefficients of lagged perceived financial difficulties are not different from zero in the poverty equation.

In all, results indicate the existence of a relationship between financial difficulties and monetary poverty but it is difficult to disentagle the origin of what could be understood as a vicious cycle of economic deprivation.

We assess the statistical fit of the different models using Akaike and Bayesian Information Criteria (AIC and BIC, respectively) for model selection (see HernándezQuevedo, Jones, and Rice, 2008). Formally,

$$
\begin{gathered}
A I C=-2 \ln L+2 q \\
B I C=-2 \ln L+(\ln M) q
\end{gathered}
$$

where $q$ is the number of parameters in each specification and $M$ the number of individual-wave observations.

Table 8 shows the results for the AIC and BIC criteria of all models. The comparison between the results for Model 1 and 3 indicates that including 'current 
Table 7: Main results for the bivariate RE probits for $S_{t}$ and $P_{t}$ (Model 3) and the ordered RE probit model for $S_{t}$ and bivariate RE probit for $P_{t}$ (Model 4) including current poverty status

\begin{tabular}{lll|ll}
\hline \multicolumn{3}{c|}{ Model 3 } & \multicolumn{2}{c}{ Model 4} \\
\hline & $S_{t}$ & $P_{t}$ & $S_{t}$ & $P_{t}$ \\
\hline$S_{t-1}$ & $0,44^{* * *}$ & $0,13^{* * *}$ & & \\
$S_{t-1}[1]$ & & & $0,47^{* * *}$ & $-0,12$ \\
$S_{t-1}[2]$ & & & $0,73^{* * *}$ & $-0,08$ \\
$S_{t-1}[3]$ & & & $1,08^{* * *}$ & $-0,04$ \\
$S_{t-1}[4]$ & & & $1,25^{* * *}$ & 0,08 \\
$S_{t-1}[5]$ & & & $1,30^{* * *}$ & 0,28 \\
$S_{0}$ & $0,75^{* * *}$ & $0,37^{* * *}$ & & \\
$S_{0}[1]$ & & & $0,67^{* * *}$ & $0,21^{* * *}$ \\
$S_{0}[2]$ & & & $1,27^{* * *}$ & $0,40^{* * *}$ \\
$S_{0}[3]$ & & & $1,80^{* * *}$ & $0,63^{* * *}$ \\
$S_{0}[4]$ & & & $1,97^{* * *}$ & $0,76^{* * *}$ \\
$S_{0}[5]$ & & & $2,31^{* * *}$ & $0,89^{* * *}$ \\
$P_{t}$ & $0,22^{* * *}$ & & $0,20^{* * *}$ & \\
$P_{t-1}$ & 0,01 & $0,74^{* * *}$ & $0,08^{* * *}$ & $0,74^{* * *}$ \\
$P_{0}$ & $0,23^{* * *}$ & $0,93^{* * *}$ & $0,14^{* * *}$ & $0,83^{* * *}$ \\
\hline eps1 & \multicolumn{2}{c|}{$0,73^{* * *}$} & \multicolumn{2}{|c}{$0,68^{* * *}$} \\
eps2 & \multicolumn{2}{c|}{$0,76^{* * *}$} & \multicolumn{2}{c}{$0,74^{* * *}$} \\
\hline rho & \multicolumn{2}{c|}{$0,32^{* * *}$} & \multicolumn{2}{c}{$0,25^{* * *}$} \\
\hline
\end{tabular}

Source: PSELL3/EU-SILC, 2003-2011, authors computation. 
Table 8: AIC and BIC for the different model specifications

\begin{tabular}{lcccc}
\hline & Model 1 & Model 2 & Model 3 & Model 4 \\
\hline lnL & $-14916,80$ & $-46647,20$ & $-14906,20$ & $-46623,10$ \\
q (parameters) & 115 & 135 & 116 & 136 \\
M (obs) & 35179 & 35179 & 35179 & 35179 \\
ln M & 10,47 & 10,47 & 10,47 & 10,47 \\
& & & & \\
AIC & 30063,6 & 93564,4 & 30044,4 & 93518,2 \\
BIC & 31037,4 & 94707,6 & 31026,7 & 94669,9 \\
\hline
\end{tabular}

Source: PSELL3/EU-SILC, 2003-2011, authors computation.

Note:

Model 1: Bivariate random effect probit model for $P_{t}$ and $S_{t}$

Model 2: Bivariate random effect probit model for $P_{t}$ and ordered for $S_{t}$

Model 3: Bivariate random effect probit model for $P_{t}$ and $S_{t}$ including $P_{t}$ as a covariate

Model 4: Bivariate random effect probit model for $P_{t}$ and ordered for $S_{t}$ including $P_{t}$ as a covariate

poverty status' in the perceived financial difficulties equation improves the statistical fit of the model. And exactly the same in the case of Models 2 and 4. Moreover, there is no contradiction between AIC and BIC.

\section{Conclusions}

The aim of this paper was to analyse whether income poverty and perceived finacial difficulties are dynamically interrelated. Our results suggest that this is the case but vary according to some specifications. When focusing on binary status variables, no evidence of feedback effect from past income poverty (perceived fincial difficulties) on current perceived financial difficulties (income poverty) was found. However, such cross-effects appeared when modelling perceived financial difficulties as an ordinal variable. 


\section{References}

Alessie, R., S. Hochguertel, And A. Van Soest (2004): "Ownership of stocks and mutual funds: A panel data analysis," The Review of Economics and Statistics, 86(3), 783-796.

Amuedo-Dorantes, C., and R. Serrano-Padial (2010): "Labour market flexibility and poverty dynamics: Evidence from Spain," Labour Economics, 17(4), 632-642.

Ayllón, S. (2013a): "From Stata to aML," Stata Journal, 1-20.

(2013b): "Understanding poverty persistence in Spain," SERIEs, 4(2), $201-233$

BiEWEN, M. (2009): "Measuring state dependence in individual poverty histories when there is feedback to employment status and household composition," Journal of Applied Econometrics, 24(7), 1095-1116.

Bottan, N., and R. Perez Truglia (2011): "Deconstructing the hedonic treadmill: is happiness auto-regressive?," Journal of Socio-Economics, 40, 224-236.

Bourguignon, F. (2006): "From income to endowments: the difficult task of expanding the income poverty paradigm," in Poverty and Inequality, ed. by D. Grusky, and R. Kanbur. Stanford University Press.

Buddelmeyer, H., And L. CAi (2009): "Interrelated dynamics of health and poverty," IZA Discussion Papers 4602, Institute for the Study of Labor (IZA).

CAI, L. (2009): "Effects of Health on Wages of Australian Men," The Economic Record, 85(270), 290-306.

(2010): "The relationship between health and labour force participation: Evidence from a panel data simultaneous equation model," Labour Economics, 17(1), 77-90.

CAI, L., And G. Kalb (2006): "Health status and labour force participation: evidence from Australia," Health Economics, 15(3), 241-261.

Cappellari, L., and S. P. Jenkins (2004): "Modelling low income transitions," Journal of Applied Econometrics, 19(5), 593-610.

Clark, A. E., C. D’Ambrosio, and S. Ghislandi (2013): "Poverty and WellBeing: Panel Evidence from Germany," PSE Working Papers hal-00814659, HAL.

Deaton, A. (2010): "Price Indexes, Inequality, and the Measurement of World Poverty," American Economic Review, 100(1), 5-34. 
Devicienti, F., F. Groisman, and A. Poggi (2010): "Are informality and poverty dynamically interrelated? Evidence from Argentina," Research on Economic Inequality, 18, 79-106.

Devicienti, F., And A. Poggi (2011): "Poverty and social exclusion: two sides of the same coin or dynamically interrelated processes?," Applied Economics, 43(25), $3549-3571$.

Fusco, A. (2013): "The dynamics of perceived financial difficulties in Luxembourg," mimeo.

Fusco, A., And N. Islam (2012): "Understanding the drivers of low income transitions in Luxembourg," Research on Economic Inequality, 20, 367-391.

Fusco, A., P. Van Kerm, A. Alieva, L. Bellani, F. Etienne-Robert, A.C. Guio, I. Kyzyma, K. Leduc, P. Ligeois, M.-N. Pi Alperin, A. Reinstadler, E. Sierminska, D. Sologon, P. Thill, M. Valentova, and B. Voicu (2013): "Luxembourg: has inequality grown enough to matter?," in Changing Inequalities and Societal Impacts in Rich Countries: Thirty Countries Experiences, ed. by B. Nolan, N. B. Salverda, Wiemer, D. Checchi, I. Marx, A. McKnight, I. Tth, and H. Van de Werfhorst. Oxford University Press.

HaAn, P., AND M. Myck (2009): "Dynamics of health and labor market risks," Journal of Health Economics, 28(6), 1116-1125.

Heckman, J. J. (2001): "Micro Data, Heterogeneity, and the Evaluation of Public Policy: Nobel Lecture," Journal of Political Economy, 109(4), 673-748.

HeIss, F. (2011): "Dynamics of self-rated health and selective mortality," Empirical Economics, 40(1), 119-140.

Hernández-Quevedo, C., M. Jones, and N. Rice (2008): "Persistence in health limitations: A European comparative analysis," Journal of Health Economics, 27, 1472-1488.

Jenkins, S. P. (2011): Changing Fortunes: Income Mobility and Poverty Dynamics in Britain. Oxford University Press.

KAYA, O. (2013): "Is perceived financial inadequacy persistent?," Review of Income and Wealth, pp. n/a-n/a.

Litwin, H., And E. SaPir (2009): "Perceived Income Adequacy Among Older Adults in 12 Countries: Findings from the Survey of Health, Ageing, and Retirement in Europe," The Gerontologist, 49(3), 397-406.

Michaud, P. C., and K. Tatsiramos (2011): "Fertility and female employment dynamics in Europe: the effect of using alternative econometric modeling assumptions," Journal of Applied Econometrics, 26(4), 641-668. 
Mundlak, Y. (1978): "On the Pooling of Time Series and Cross Section Data," Econometrica, 46(1), 69-85.

Newman, C., L. Delaney, and B. Nolan (2008): "A Dynamic Model of the Relationship Between Income and Financial Satisfaction: Evidence from Ireland," The Economic and Social review, 39(2), 105-30.

Nicoletti, C., F. Peracchi, and F. Foliano (2011): "Estimating Income Poverty in the Presence of Missing Data and Measurement Error," Journal of Business \&6 Economic Statistics, 29(1), 61-72.

Pudney, S. (2008): "The dynamics of perception: modelling subjective wellbeing in a short panel," Journal of the Royal Statistical Society Series A, 171(1), 21-40.

Ravallion, M. (1996): "Issues in Measuring and Modelling Poverty," Economic Journal, 106(438), 1328-43.

Rochut, J., And P. VAN Kerm (2010): "The link between unemployment and health," in 27emes Journees de Microeconomie Appliquee.

Skrondal, A., And S. Rabe-Hesketh (2013): "Handling initial conditions and endogenous covariates in dynamic/transition models for binary data with unobserved heterogeneity," Journal of the Royal Statistical Society: Series C (Applied Statistics), pp. n/a-n/a.

STATEC (2013): "Rapport travail et cohsion sociale," No. 116 in Cahier Economique. Statec.

Stewart, M. B. (2007): "The interrelated dynamics of unemployment and lowwage employment," Journal of Applied Econometrics, 22(3), 511-531.

Stoller, M. A., And E. P. Stoller (2003): "Perceived Income Adequacy among Elderly Retirees," Journal of Applied Gerontology, 22(2), 230-251.

TAYlor, M. (2011): "Measuring Financial Capability and its Determinants Using Survey Data," Social Indicators Research, 102(2), 297-314.

Weber, A. (2002): "State dependence and wage dynamics. A heterogeneous Markov chain model for wage mobility in Austria," Economic Series 114, Institute for Advanced Studies (Vienna).

WoOLDRIDGE, J. M. (2005): "Simple solutions to the initial conditions problem in dynamic, non linear panel data models with unobserved heterogeneity," Journal of Applied Econometrics, 20(1), 39-54.

Wunder, C. (2012): "Does subjective well-being dynamically adjust to circumstances?," Economics Letters, 117(3), 750-752. 